\title{
DESENVOLVIMENTO DE JOGOS EDUCATIVOS PARA PESSOAS COM NECESSIDADES ESPECIAIS ${ }^{1}$
}

\author{
DEVELOPMENT OF EDUCATIVE GAMES \\ FOR PEOPLE WITH SPECIAL NECESSITIES
}

\begin{abstract}
Alessandro Antunes Silva ${ }^{2}$
\section{RESUMO}

A cada dia tem aumentado o número de pessoas com necessidades especiais presentes em Instituições de Ensino, graças a leis que vieram a tentar acabar com o preconceito e a falta de informação e ajudar na inclusão de dEficientes $^{3}$. A utilização de softwares e ferramentas adaptados para as necessidades de determinados grupos de pessoas é algo de grande importância, para isso, temos que tentar criar meios adequados, seja através de adaptações físicas ou virtuais, como a criação de programas adequados a cada tipo de dEficiência. Com este trabalho relataremos o desenvolvimento de alguns jogos para a utilização em aulas de ciências da $7^{\circ}$ série do Ensino Fundamental, principalmente para ser uma ferramenta de ensino a um aluno com paralisia cerebral.
\end{abstract}

Palavras chave: deficientes, Internet, software, RPG, jogos.

\begin{abstract}
The number of people who show special needs in teaching institutions has increased due to laws which were created to dicrease the prejudice, the lack of information and help in the inclusion of dEficients. Every day has been increasing the number of people with present special nee in Institutions of Teaching, thanks to laws that came to try to end with the prejudice and the lack of information and to help in the inclusion of deficient. The use of softwares and tools adapted for the needs of certain groups of people is something of great importance, that why, we have to try to create appropriate means, either through physical or virtual adaptations, as the creation of appropriate programs to each dEficiency type. With this work we will show the development of games for the use in 7th series of the Fundamental Teaching classes of sciences, mainly to be a teaching tool of to students with cerebral paralysis.
\end{abstract}

Key words: dEficient, Internet, software, RPG, games.

\footnotetext{
${ }^{1}$ Orientação e colaboração: Prof ${ }^{a}$ Liliana Maria Passerino e Regina Heidrich

${ }^{2}$ Acadêmico do Curso de Pós Graduação em Informática Educativa: Especialização em Software Educativo FEEVALE

${ }^{3} \mathrm{dEficiente} \mathrm{com} \mathrm{o} \mathrm{E} \mathrm{em} \mathrm{maiúsculo,} \mathrm{para} \mathrm{destacar} \mathrm{a} \mathrm{capacidade} \mathrm{das} \mathrm{pessoas} \mathrm{com} \mathrm{necessidades} \mathrm{especiais} \mathrm{(PNE),}$ segundo a Associação de Portadores de Deficiência, 2005. 


\section{INTRODUÇÃ ${ }^{4}$}

A popularização do computador com aplicação em diversas áreas do conhecimento é, hoje, fato inquestionável, assim também ocorre na educação. É cada vez maior o desenvolvimento e utilização de softwares educacionais. Neste sentido, a escola tem necessidade de se renovar a cada dia que passa, caso contrário corre o risco de não ser suficientemente atrativa aos alunos de hoje, sejam eles com necessidades especiais ou não.

Uma das características da infância com certeza é a atividade de brincar. É através desta atividade que a criança constrói sua aprendizagem acerca do mundo em que vive, da cultura, do meio em que está inserida. Os jogos são uma porção, uma pequena parte desta atividade de construção da criança que se transfere para o adolescente.

Deve-se a está conscientização a teóricos como Piaget, Vigotsky, entre outros, que contribuíram para um novo processo no trabalho pedagógico, idealizando novas teorias sobre o que deveria ser uma escola e sobre a importância do jogo no ensino. Também Gardner com sua Teoria das Inteligências Múltiplas mudou nossa visão das capacidades cognitivas do ser humano.

Portanto, é a ai que está a motivação para o desenvolvimento do jogo computacional, que possa ser utilizado por todos os alunos, não só por aquele com necessidades especiais. Pois a nosso ver, é mais que uma ferramenta, da forma que for construído e enfocando os aspectos relevantes das disciplinas a qual foi desenvolvido pode ser um motivador, um meio mais interessante ao aluno para conhecer e aprender os conteúdos das disciplinas normais dos diversos cursos. O jogo computacional pode ser desenvolvido de acordo com as necessidades dos alunos, da escola e de seus professores, assim, se adequando a cada meio e aos poucos se tornando um novo instrumento de ensinar.

\section{PARALISIA CEREBRAL}

Paralisia Cerebral é uma lesão de alguma ou algumas partes do cérebro que pode acontecer durante a gestação, durante o parto ou após o nascimento, ainda no processo de amadurecimento do cérebro da criança. É uma lesão provocada, muitas vezes, pela falta de oxigenação das células cerebrais (Andrade, 1999).

Em todas as formas de paralisia cerebral, pode ser difícil compreender a fala das crianças afetadas, pois a criança tem dificuldade para controlar os músculos envolvidos na fala. A maioria das crianças com paralisia cerebral apresenta outras incapacidades (ex., inteligência inferior à normal). Outras apresentam retardo mental grave. Contudo, aproximadamente $40 \%$ das crianças com paralisia cerebral possuem uma inteligência normal ou quase normal. Cerca de $25 \%$ das crianças com paralisia cerebral (mais freqüentemente as com o tipo espástico) apresentam epilepsia (crises convulsivas). (BOBATH, 1978)

De acordo com Andrade(1999) o termo "Paralisia Cerebral" apesar de mais usual, não é a definição mais adequada, pois na realidade o cérebro não se encontra paralisado, mas sim impossibilitado de gerenciar as funções motoras. Para ele o correto seria "Doença Motora de Origem Cerebral" (D.M.O.C.), como já é conhecida internacionalmente.

\footnotetext{
${ }^{4}$ Este trabalho foi desenvolvido durante o estágio I do curso de Licenciatura em Computação do Centro Universitário
Feevale. 
Devido às dEficiências motoras, os portadores de D.M.O.C. apresentam uma imobilidade em vários níveis, podendo causar problemas de coluna (alterações), acúmulo de secreções respiratórias, prisão de ventre, entre outros. Além disso, muitos apresentam crises convulsivas-epiléticas, agitação psicomotora, agressividade, depressão, etc.

\section{ASPECTOS RELEVANTES NO DESENVOLVIMENTO DE JOGOS}

\section{EDUCATIVOS}

Desenvolver um jogo educativo requer além de uma análise detalhada dos requisitos de software, uma definição com relação a plataforma mais adequada. Para a construção dos jogos foram analisados diversos softwares que poderiam auxiliar nesse desenvolvimento, entre eles temos:

- “The Games Factory", também conhecido como TGF, que é um programa para desenvolvimento de jogos da linha clique e arraste. Onde o usuário por meio de diversos opções dentro da ferramenta pode inserir figuras e animá-las, dessa forma desenvolvendo os jogos de uma maneira bastante intuitiva.

- "Multimedia Fusion 1.5", conhecido como MMF, esta é também uma ferramenta para desenvolvimento de jogos nos mesmos moldes clique e arraste. Seus games são salvos em um único .exe, diferentemente do TGF, onde o .exe e .gam devem ser distribuídos juntos para que os jogos funcionem.

- "RPG Maker", este software também foi desenvolvido na mesmo método clique e arraste, onde muitas imagens e ações que já estão préconfiguradas e podem ser acessadas e utilizadas para se construir um jogo nos moldes do RPG.

Depois de uma análise, optou-se para o desenvolvimento dos jogos, o Imagine e o Game Maker.

O Imagine é uma ferramenta para o desenvolvimento de projetos. Foi desenvolvida por Andrej Blaho, Ivan Kalas, Lubomir Salanci, Peter Tomcsanyi da cidade de Bratislava, na Eslováquia e foi trazido, traduzido e distribuído pela empresa CNOTINFOR BRASIL Educação e Tecnologia, Ltda.

Ele é uma nova geração da linguagem Logo, desenvolvida para usuários que querem realizar uma ampla variedade de atividades como desenhar e animar, criar para a Internet, programar em Logo tradicional, criar aplicações multimídia, usar entrada e saída de voz, trabalhar com modelagem, construir um ambiente de aprendizagem específico de um domínio, comunicar idéias, criar apresentações, desenvolver projetos e micro-mundos para qualquer disciplina do ensino, trabalhar com computação, entre outros.

A partir dessa plataforma, foram desenvolvidos um jogo da memória e um jogo de pintura.

O Game Maker foi utilizado para desenvolver o RPG. É uma ferramenta completa que pode ser usado para criar jogos de computador em duas dimensões para Windows. A aplicação inclui uma ferramenta de criação de gráficos integrada que pode ser usada para criar sprites, uma interface de arraste e cole, faz isso tudo com uma 
linguagem de programação que é semelhante às linguagens de programação como $\mathrm{C}++$, Pascal e Basic.

Através do Game Maker foi desenvolvido o RPG "Plantão Médico" que procura simular um médico num hospital auxiliando seus pacientes.

\section{MODELAGEM E ASPECTOS PEDAGÓGICOS}

A teoria pedagógica com que foram desenvolvidos os softwares foram a Teoria das Inteligências Múltiplas e a Teoria de Piaget, através do incentivo de diversas atividades lúdicas que trabalham a inteligência espacial, lógico-matemática e a Interpessoal. O jogo de pintura, o quebra-cabeças e o jogo da memória exploram a inteligência espacial a medida em que trabalha a percepção das formas do desenho associado a aspectos reais da anatomia humana, assim como o sentido de direção bem como o reconhecimento de imagens que pertençam a um mesmo elemento.

Já o RPG "Plantão Médico" trabalha tanto a inteligência Espacial, a LógicoMatemática, e até mesmo a inteligência Interpessoal já que o RPG pode ser jogado com o auxílio de um colega, e mesmo no ambiente do jogo o personagem central tem que se relacionar com outros personagens, respondendo perguntas e ajudando-os.

O programa atualmente conta com três jogos, mas está previsto o desenvolvimento de mais componentes utilizando outras ferramentas de construção, trabalhando outros assuntos da disciplina. $\mathrm{O}$ tema abordado pelos softwares foi o Corpo Humano (Esqueleto e Sistema Digestivo).

Foi desenvolvido um jogo da memória com imagens e palavras do esqueleto humano, onde o aluno terá que relacioná-las. Um jogo de pintura, em que o usuário deverá pintar as diferentes partes do sistema digestivo e o esqueleto humano de acordo com uma legenda ao lado. E finalmente um RPG, onde o aluno faz o papel de um médico e deve auxiliar seus pacientes, respondendo a suas perguntas. $\mathrm{O}$ interessante a ser observado nesses jogos, é que para ser utilizado por um aluno com Paralisia Cerebral, precisa-se verificar sua dEficiência, e adaptar o jogo para cada necessidade. No caso para o qual desenvolvemos os jogos, o aluno conseguia movimentar a mão esquerda, mas sem conseguir pressionar o botão e mover o mouse ao mesmo tempo. Assim, os jogos foram criados de maneira que seja preciso utilizar apenas um comando de cada vez. Nos exemplos, todos os comandos envolvem apenas o apertar o botão, mover o mouse, ou utilizar as setas direcionais uma de cada vez. 


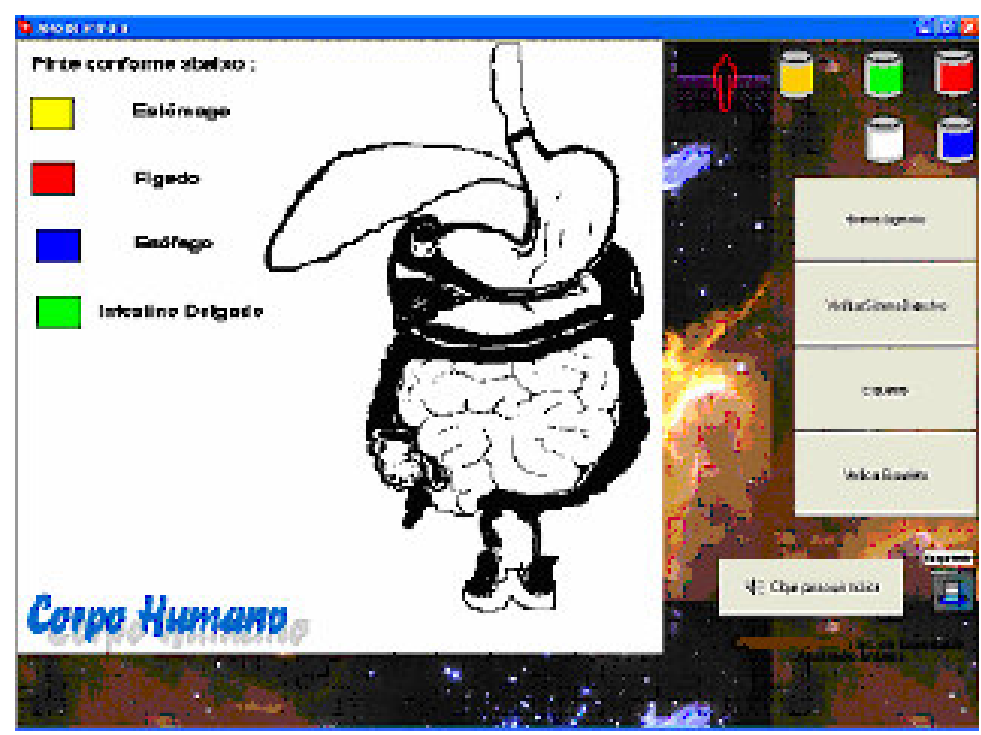

Figura 1 - Tela do Jogo de Pintura 1

A figura anterior é a tela inicial do "Jogo da Pintura" desenvolvido através do software "Imagine,2005", onde o aluno tem a sua disposição um menu com duas opções de imagens, o sistema digestivo e o esqueleto humano. Em cima há uma opção de cores (baldes de tinta), onde o usuário terá que clicar sobre a cor desejada e pintar o desenho de acordo com a legenda que está a esquerda do desenho. Um simples clique e o desenho é preenchido com a cor selecionada. Há também um botão a direita, logo abaixo do menu de escolha de imagens, onde o usuário poderá iniciar uma música para ouvir enquanto joga e também um menu para iniciar a impressão do desenho quando tiver terminado a atividade. Para sair do jogo a qualquer tempo, clica-se no " $X$ ", no canto direito superior, ou então aperta-se a tecla "Esc" no teclado. 


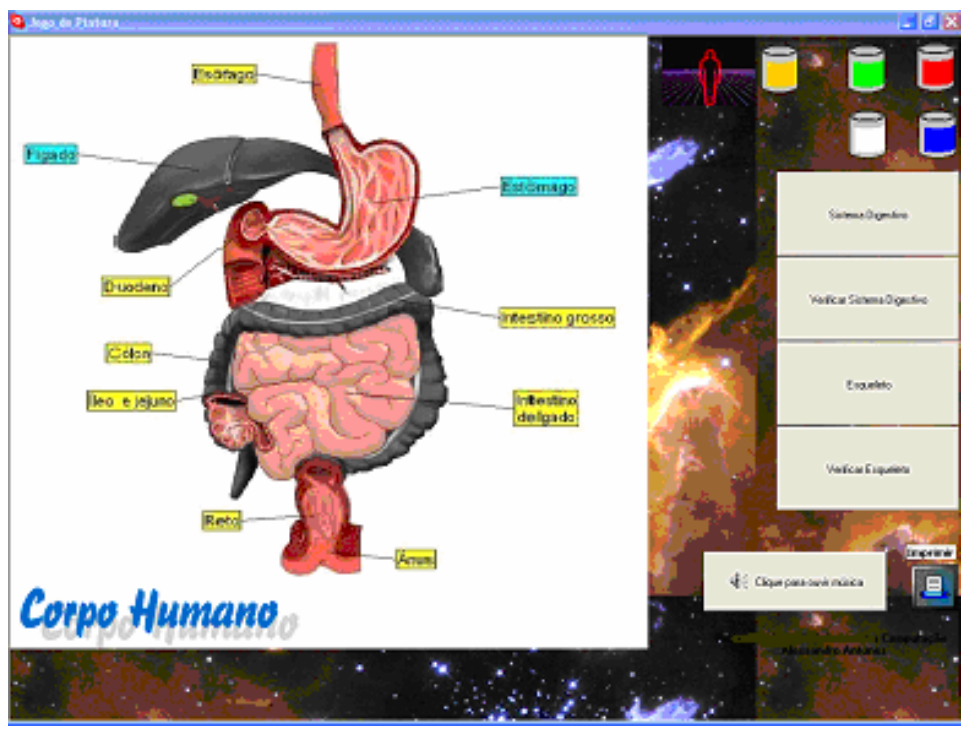

Figura 2 - Tela do Jogo de Pintura com o desenho pronto para o aluno avaliar seus conhecimentos.

A tela acima mostra a seleção que está logo abaixo do botão de opção de desenhos, "Sistema Digestivo", que é o botão de seleção "Verificar Sistema Digestivo", onde o aluno pode averiguar se completou o desenho corretamente de acordo com a legenda.

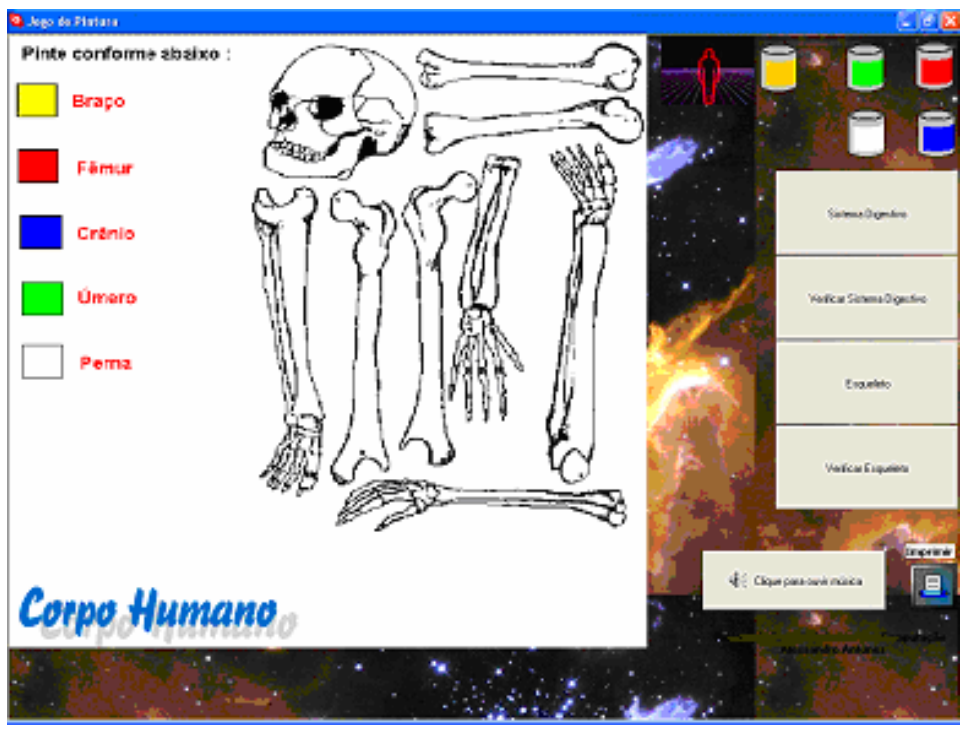

Figura 3 - Tela do Jogo de Pintura

Aqui temos o terceiro "botão" de escolha, que é a atividade de pintar o "Esqueleto", onde o usuário deve pintar o esqueleto de acordo com a legenda ao lado esquerdo do software. 


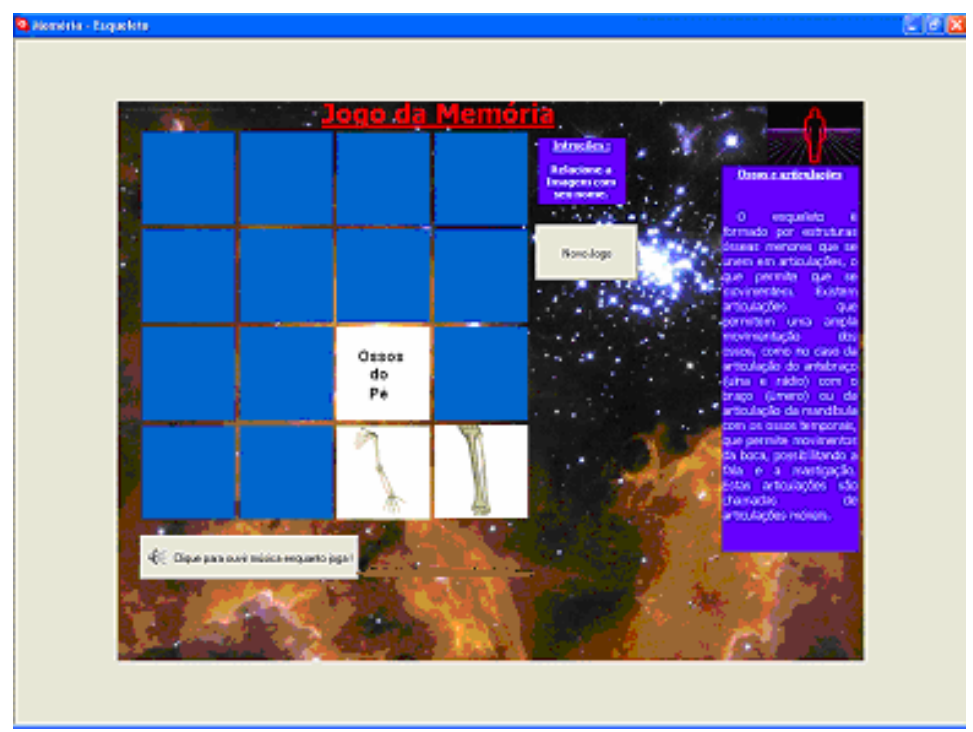

Figura 4 - Tela do Jogo da Memória

Memória é um jogo de concentração e memorização, bastante conhecido e com centenas de variações, onde o objetivo principal é procurar e unir os pares de blocos idênticos corretamente. Em caso de resposta errada, os blocos são novamente virados para baixo. O jogo termina quando todos os pares são encontrados. Neste caso específico, o assunto abordado foi o esqueleto humano. Cada figura (osso) tem o seu par (nome), achando o par, os blocos são retirados do conjunto e colocados a direita, não o encontrando, são virados novamente. O usuário clica no bloco e ele mostrará a figura por alguns segundos, dando tempo do usuário clicar em outra que ele ache que seja o seu par. Há também uma caixa de texto, a direita, com algumas informações sobre o esqueleto humano e um botão para iniciar uma "música" ou pará-la, logo abaixo dos blocos, a esquerda. Para sair do jogo deve-se clicar no " $\mathrm{X}$ " no canto direito superior da tela, ou então apertar a tecla "Esc". 


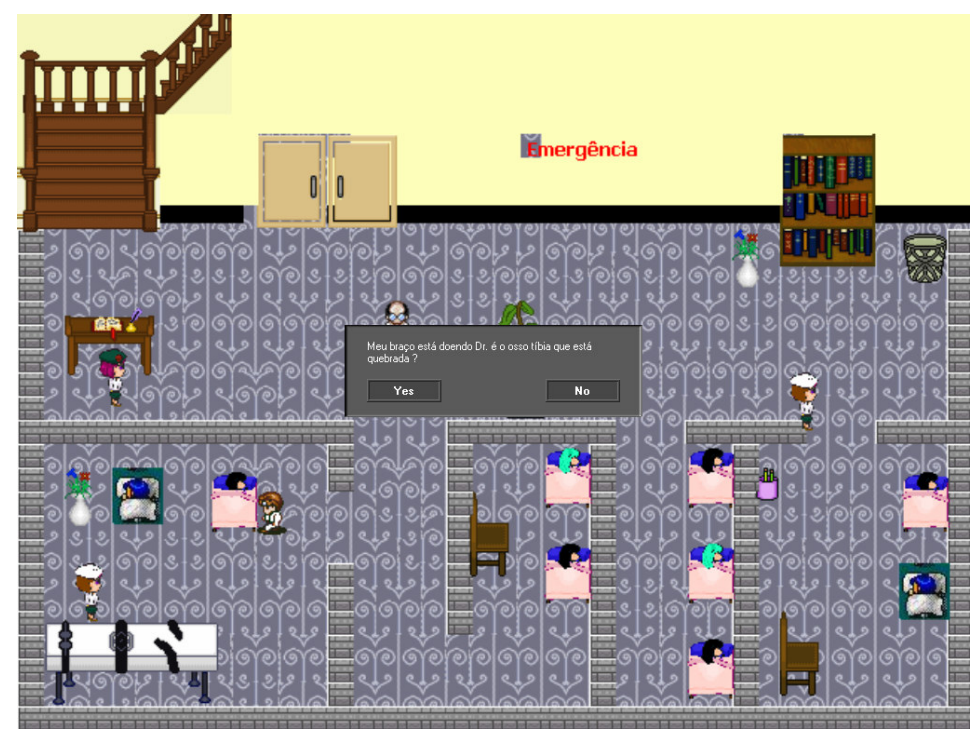

Figura 5 - Tela do nível 1, primeiro andar, do jogo RPG.

Na figura anterior temos o primeiro nível do jogo de RPG, que demos o nome de Plantão Médico, onde o usuário controlará um "médico" e deverá responder a perguntas de seus pacientes. As perguntas são todas relacionadas a disciplina de ciências da $1^{\circ}$ etapa do $4^{\circ}$ ciclo do Ensino Fundamental.

O usuário se movimentará na tela por meio das teclas direcionais, e quando o personagem comandado pelo usuário encostar em algum objeto, se abrirá uma janela com alguma pergunta ao jogador que deverá responder selecionando entre as respostas "sim" ou "não", ou outras alternativas. Na figura de uma escada o personagem controlado pelo jogador terá acesso ao segundo andar do "Hospital" que é um segundo nível no jogo. Na prateleira com livros será desenvolvido uma espécie de banco de dados, uma biblioteca, para consulta a assuntos referentes ao corpo humano. Apertando a tecla "Esc" a qualquer tempo o usuário poderá deixar o jogo, ou então se dirigir até a porta de entrada/saída que está ao lado da escada na parte superior da imagem.

\section{CONCLUSÃO}

Através desta pesquisa para desenvolvimento desses jogos, podemos constatar que, apesar do grande avanço tecnológico ocorrido nos últimos anos com o invento do computador e da Internet, e seu acesso nas escolas, ainda há uma lacuna a ser preenchida, que é oportunizar o acesso a pessoas com necessidades especiais ao computador, por meio de softwares e ferramentas adequadas. Essas ferramentas muitas vezes podem ser facilmente adaptadas para o uso do aluno. Muitas vezes essas adaptações podem transformar a experiência em sala de aula do aluno com alguma necessidade em algo mais prazeroso e eficiente.

Talvez entre todos os tipos de jogos, o RPG, também conhecido como Jogo de Representação, seja um dos mais interessantes e completos jogos para se ensinar, pois através dele se pode trabalhar qualquer disciplina, dependendo é claro da capacidade criativa do narrador, ou no caso de ser computadorizado, do desenvolvedor. Pois o 
mesmo pode se desenrolar em qualquer ambiente, e aplicado nos ensinos de história, geografia, português, matemática, física, entre outros.

Para finalizar, devemos enfatizar que, cabe também ao profissional de Informática Educativa buscar e desenvolver ferramentas que possam auxiliar as pessoas com necessidades especiais ou não no processo de aprendizagem.

\section{REFERÊNCIAS BIBLIOGRÁFICAS}

ANDRADE, Jorge M. P. Paralisias Cerebrais. Disponível em: <www.defnet.org.br> Acesso: 20 de novembro de 2005.

BECKER, Fernando. Ensino e construção do conhecimento: o processo de abstração reflexionante. Ed. Manole. Porto Alegre, 1993.

BOBATH, K. \& BOBATH, B. O Desenvolvimento Motor nos Diferentes Tipos de Paralisia Cerebral. Ed. Manole. São Paulo, 1978.

BRENELLI, Rosely P. O Jogo como espaço para pensar. Editora Papirus. São Paulo, 2003.

FEFISA, Associação de Portadores de Deficiência. Disponível em:

$<\mathrm{http}$ ://ies.portadoresdedeficiencia.vilabol.uol.com.br/index.html>. Acesso em $26 \mathrm{de}$ novembro de 2005.

GAME MAKER. Software Game Maker. Disponível em:

$<$ http://www.gamemaker.nl/> Acesso em 26 de novembro de 2005.

GARDNER, Howard. Inteligências Múltiplas - A Teoria na Prática. Ed. Artes Médicas. Porto Alegre, 1999.

GARDNER, Howard.Estruturas das Inteligências Múltiplas. Ed. Artes Médicas. Porto Alegre, 1994.

IMAGINE. Software Imagine. Disponível em: $<$ http://www.cnotinfor.com.br/cnotinfor/imagine.htm>. Acesso em 22 de novembro de 2005.

LDB. Lei de Diretrizes e Bases da Educação. Lei $n^{\circ}$ 9.394, de 20 de dezembro de 1996.

LIMA, E. S. Ciclos de formação: uma reorganização do tempo escolar. 107 Editora. São Paulo, 2000.

MARTINS, J. G.; MOCO, S. S.; MARTINS, A. R.; BARCIA, R. M. Realidade Virtual Através de Jogos na Educação. Florianópolis, 2001.

PEDAGOGO BRASIL. Site de notícias relacionada a pedagogia. Disponível em: $<$ http://www.pedagobrasil.com.br/formasp.asp > . Acesso em 20 de novembro de 2005.

PIAGET, J.; Inhelder, BÄRBEL. A psicologia da criança. Editora Difel. Rio de Janeiro, 2003. 
REDE RPG. RPG Notícias. Disponível em: <http://www.rederpg.com.br>. Acesso em 20 de novembro de 2005.

SILVEIRA, R. S; BARONE, D. A. C. Jogos Educativos computadorizados utilizando a abordagem de algoritmos genéticos. 1998. 